\title{
Altered action of glucagon on human liver in Type 2 (non-insulin-dependent) diabetes mellitus
}

\author{
P.Arner ${ }^{1}$, K. Einarsson ${ }^{1}$, S. Ewerth ${ }^{1}$ and J.N. Livingston ${ }^{2}$ \\ ${ }^{1}$ Departments of Medicine and Surgery, Huddinge Hospital, Karolinska Institute, Stockholm, Sweden and \\ ${ }^{2}$ Department of Medicine, University of Rochester, School of Medicine and Dentistry, Rochester, NY, USA
}

\begin{abstract}
Summary. Glucagon may play a role in the metabolic derangements of overt Type 2 (non-insulin-dependent) diabetes mellitus. We therefore have evaluated the early steps in glucagon action by investigating the hormone-sensitive adenylyl cyclase system in liver membranes from seven Type 2 diabetic patients with fasting hyperglycaemia and two-fold elevations in plasma glucagon. The comparison was made with seven control subjects matched for age, sex and body weight. Glucagon receptor binding was almost identical in the two groups. There were, however, marked alterations in the adenylyl cyclase activity in membranes from the diabetic patients. This activity was reduced by $35-50 \%$ when compared to con-
\end{abstract}

trol activity. Basal cyclase activity, as well as the activity after stimulation with glucagon or with agents (i.e., sodium fluoride and forskolin) that act beyond the glucagon receptor, was significantly decreased ( $p<0.05, p<0.001$ respectively). In conclusion, uncontrolled Type 2 diabetes in associated with an over-all loss of responsiveness of the hormone-sensitive adenylyl cyclase in human liver, which apparently results from post-receptor alterations. This change may provide a mechanism for reducing the effect of hyperglycagonaemia in Type 2 diabetes mellitus.

Key words: Glucagon receptor, adenylyl cyclase, cyclic AMP.
The liver plays a prominent role in the regulation of glucose and ketone homeostasis. In Type 2 diabetes, glucose metabolism by the liver is altered, which contributes to the glucose intolerance found in this condition [1]. Since hyperglucagonaemia is usually present in uncontrolled Type 2 diabetes, this hormonal excess has been implicated in the overall pathophysiology of the disease [2]. It is not known, however, whether the action of glucagon on the liver is altered and whether such alterations are of importance for the metabolic expression of Type 2 diabetes mellitus.

In the present study, we examined the early steps in glucagon action on liver membranes in overt Type 2 diabetes. Liver samples were obtained during elective gall-bladder surgery from control subjects and from Type 2 diabetic patients with fasting hyperglycaemia. Studies of the glucagon receptors and the adenylyl cyclase system were conducted.

\section{Subjects and methods}

Seven Type 2 diabetic patients and seven control subjects were investigated. All of the subjects were admitted to the Huddinge Hospital for elective cholecystectomy; otherwise, they were healthy. All control subjects were drug-free. Three individuals in each group were obese; the remaining individuals were non-obese. The diabetic patients had not received insulin therapy; the duration of disease ranged from 5 to 10 years. Diabetes was considered in moderate control because the patients had elevated blood glucose levels but urine was, in general, glucose-free. Four diabetic patients were treat- ed with diet plus a short-acting sulfonylurea (glibenclamide); the remaining three received diet alone. None of the diabetic patients received any drugs besides sulphonylurea. All diabetic patients and control subjects were admitted to the hospital as inpatients 7 days prior to surgery and maintained on an isocaloric diet of $45 \%$ carbohydrates, $20 \%$ protein and $35 \%$ fat. During this hospitalisation period, sulfonylurea therapy was discontinued in the 4 diabetic patients receiving the drug. It was not necessary to give the latter patients additional antidiabetic therapy during the study period because their glucose homeostasis deteriorated only slightly following the withdrawal of the medication. The diabetic patients and control subjects also participated in another study in which the hepatic insulin receptor was characterized. These results are presented elsewhere [3]. This study was approved by the Ethical Committee of the Karolinska Institute. Informed consent was obtained from each subject after he or she was given a detailed description of the study.

On the morning of day 7 , venous blood samples were obtained after an overnight fast for the measurement of plasma levels of glucose, insulin and glucagon (using antiserum E7) as described in detail previously [4]. A $100 \mathrm{~g}$ oral glucose load was given and plasma glucose was followed for $2 \mathrm{~h}$. The average body weight was obtained from tables computed by Documenta Geigy.

On the morning of day 8 after an overnight fast, general anaesthesia was induced with a short-acting barbiturate and maintained by phentanyl and a nitrous-oxygen mixture. At the beginning of surgery a 2-g liver biopsy was taken from the left lobe of the liver. Morphologic evidence of slight fatty acid infiltration was observed in the liver of one diabetic patient and one control subject. No other histological abnormalities were noted.

One part ( $1 \mathrm{~g}$ ) of the liver biopsy was immediately homogenized and centrifuged to obtain a membrane fraction as described in detail [4]. The protein content was determined [5] and the material was frozen at $-80^{\circ} \mathrm{C}$. The samples were sent to Rochester, NY, USA for further analysis of specific glucagon binding, glucagon degradation and adenylyl cyclase activity as previously described [4]. The code 
Table 1. Clinical data of control subjects and diabetes patients

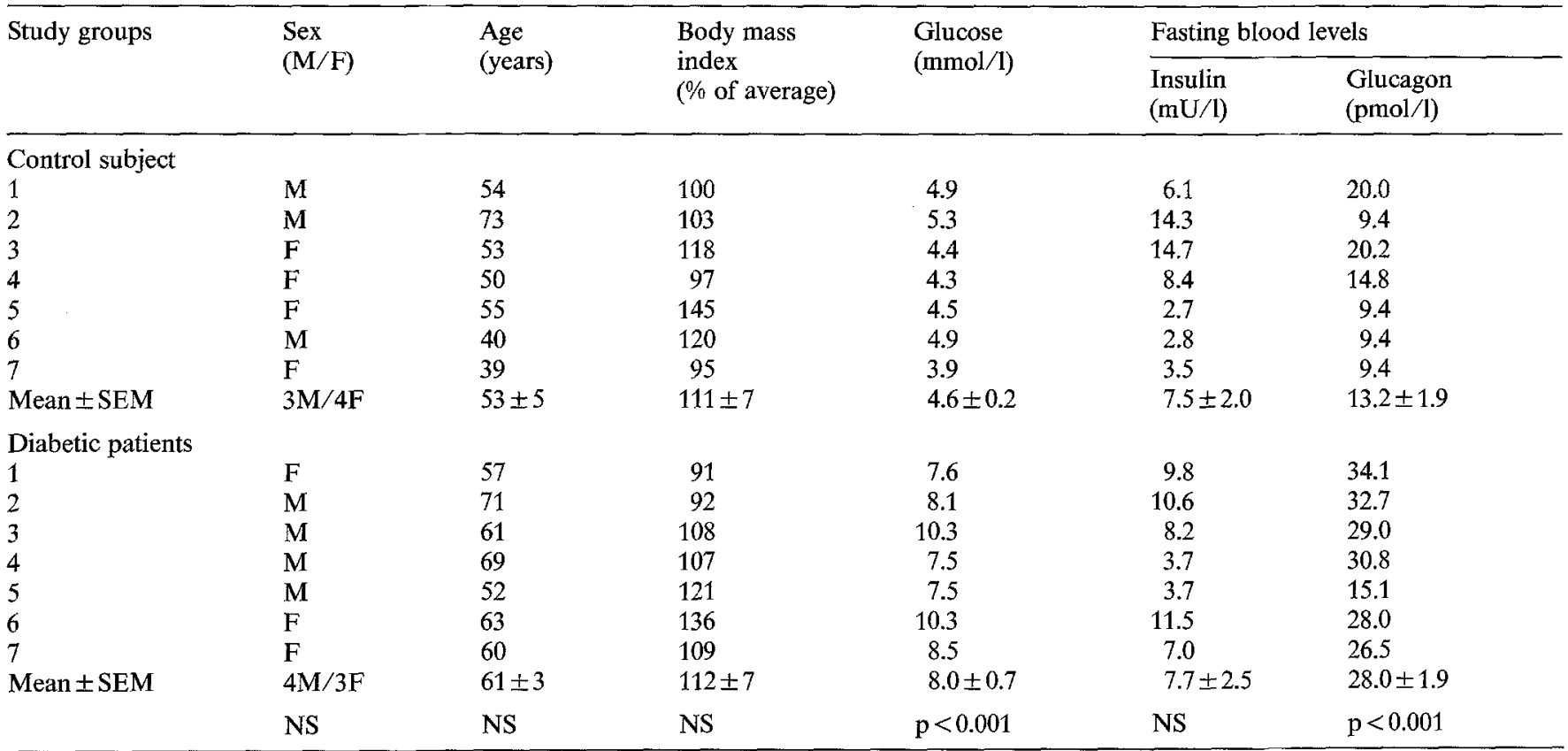

NS = not significant

with respect to the diagnosis of diabetes was not known to the person who analysed the liver samples until after the final results were obtained. In brief, specific glucagon binding was measured by incubating liver membranes $\left(20 \mu \mathrm{g}\right.$ protein/assay) for $30 \mathrm{~min}$ at $21^{\circ} \mathrm{C}$ with $0.3,1.3$ and $10 \mathrm{mmol} / \mathrm{L}$ of ${ }^{125} \mathrm{I}$-glucagon in the presence or $\mathrm{ab}$ sence of $1 \mathrm{umol} / 1$ of native glucagon. To measure adenylyl cyclase activity, liver membranes ( $10 \mu \mathrm{g}$ protein/assay) were incubated in a buffer containing $1 \mu \mathrm{mol} / \mathrm{l}$ of GTP with the indicated glucagon concentration, sodium fluoride $(10 \mathrm{mmol} / \mathrm{l})$, or forskolin $(100 \mu \mathrm{mol} / 1)$ for $10 \mathrm{~min}$ at $32^{\circ} \mathrm{C}$. The production of cyclic AMP from (alpha$\left.{ }^{32} \mathbf{P}\right)$-ATP was determined as described [4].

\section{Statistical analysis}

The values given are mean \pm standard error of the mean (SEM). Student's unpaired t-test and linear regression analysis were used for statistical comparison.

\section{Results}

The clinical data for each subject and patient recorded on the day preceeding cholecystectomy are given in Table 1. The diabetic patients had significant fasting hyperglycaemia and hyperglucagonaemia, with both levels approximately two-fold above normal. However, fasting insulin values in the diabetic patients did not differ from the control subjects. Values for age, sex, height and body weight were not significantly different between the two groups. Oral glucose tolerance was normal in each control subject and decreased in each diabetic patient (data not shown). A slight but not statistically significant increase in fasting blood glucose was observed at day 7 compared to day 1 in the diabetic patients. During the same period the urinary glucose output increased from $1 \pm 5$ to $29 \pm 7 \mathrm{~mol} / 24 \mathrm{~h}$ in the diabetic patients.

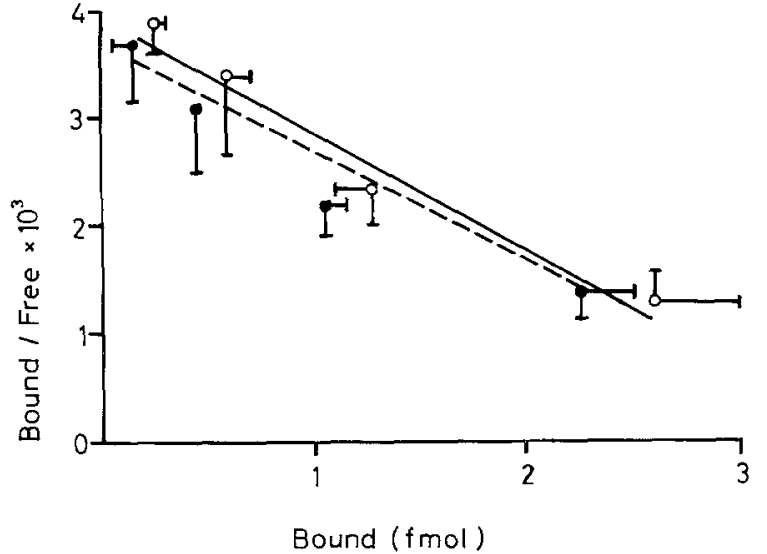

Fig. 1. Scatchard analysis of glucagon binding to liver membranes of control subjects (open circles) and diabetic patients (filled circles). The binding studies were conducted as described in Methods. Values are mean \pm SEM

Figure 1 shows the Scatchard plots [6] of specific glucagon binding for the two groups. The binding curves were almost indentical for diabetic patients and control subjects; at no hormone concentration $(0.3-10 \mathrm{nmol} / 1)$ was there any difference between the two groups. Consequently, the dissociation constant and maximum binding were similar between the groups, having values of $4 \mathrm{nmol} / \mathrm{l}$ and $4 \mathrm{fmol} / 20 \mu \mathrm{g}$ of protein respectively. In these studies, glucagon degradation was less than $10 \%$.

Cyclic AMP formation by the liver membranes from both groups was measured and the results are shown in Figure 2. In these studies adenylyl cyclase activity was stimulated by glucagon, sodium fluoride $(\mathrm{NaF})$ and forskolin. The latter two agents were used 


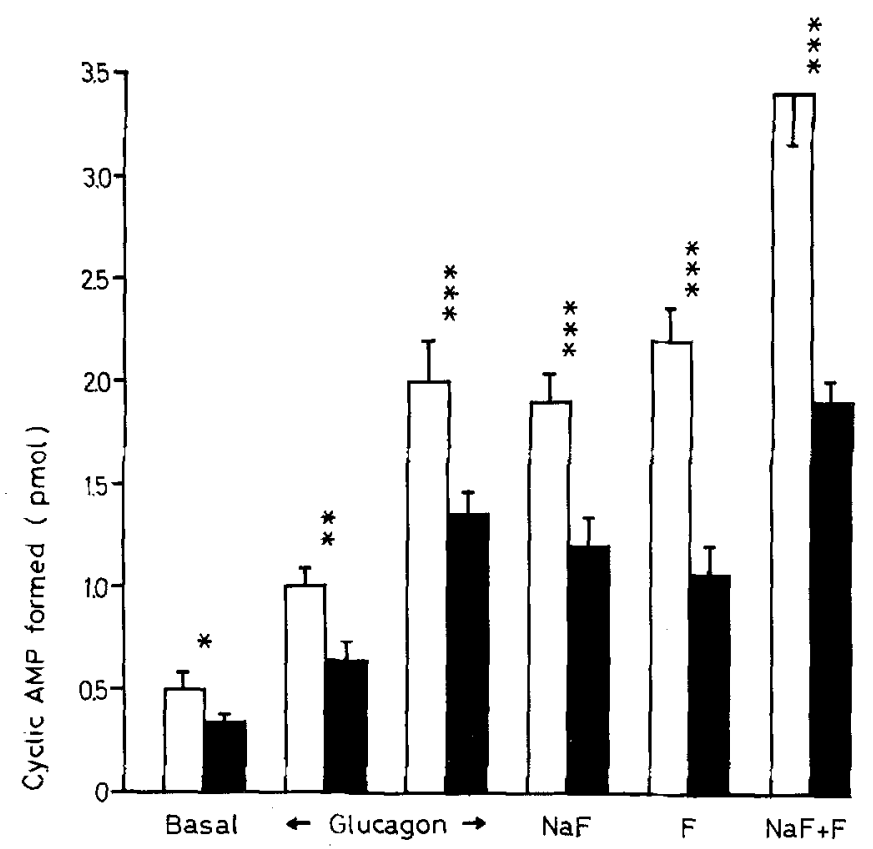

Fig. 2. Formation of cyclic AMP by liver membranes from control subjects (open bars) and diabetic patients (filled bars). The adenylyl cyclase assay was conducted as outlined in Methods. From left to right the group of bars represent the following incubation conditions: no addition (basal), glucagon $(5 \mathrm{nmol} / \mathrm{l})$, glucagon $(1 \mu \mathrm{mol} / 1)$, sodium fluoride $(10 \mathrm{mmol} / \mathrm{l})$, forskolin $(100 \mu \mathrm{mol} / \mathrm{l})$ and sodium fluoride plus forskolin $(10 \mathrm{mmol} / 1$ plus $100 \mu \mathrm{mol} / \mathrm{l})$. The results are expressed as mean $\pm S E M$. They were statistically compared using Student's t-test. ${ }^{* * *} p<0.01,{ }^{* *} p>0.01,{ }^{*} p<0.05$

because they act at sites beyond the glucagon receptor $[7,8]$. As shown, there was a highly significant $(35-50 \%, p<0.01)$ reduction of cyclic AMP formation in membranes from the diabetic patients. This decrease was observed in the basal state and with all three of the agents that stimulated the cyclase system. In both groups the effect of $1 \mu \mathrm{mol} / 1$ of glucagon was in the same order of magnitude as that obtained with $10 \mathrm{mmol} / 1$ of sodium fluoride, which indicates that a maximum effect of glucagon was reached [4]. Furthermore, the half-maximal response to glucagon was obtained with the same glucagon concentration of $5 \mathrm{nmol} / 1$.

The relationship between age, on the one hand, and glucagon binding or adenylyl cyclase, on the other hand, was investigated in the two groups. Neither glucagon binding nor cyclic AMP formation were correlated with age $(r<0.2)$.

\section{Discussion}

Glucagon stimulates glycogenolysis and ketogenesis in the liver through a long and complex series of biochemical reactions, which are initiated by glucagon activation of membrane associated adenylyl cyclase which results in enhanced cyclic AMP production [9, 10]. We show in the present report that the ability of glucagon to activate adenylyl cyclase is significantly decreased by one-third to one-half in hyperglycaemic Type 2 diabetes mellitus. This alteration was observed in the basal state and with stimulation by either of the three agents used; i.e. glucagon, $\mathrm{NaF}$ and forskolin.

Although all diabetic patients had received treatment for their disease, it is not likely that the adenylyl cyclase activity was modified by the antidiabetic therapy. All control subjects and diabetic patients were studied as inpatients one week prior to surgery. During that time they received the same diet, and sulfonylurea therapy was discontinued. It is unlikely that the findings with adenylyl cyclase are influenced by variations in the recovery of plasma membrane proteins. First, we have previously shown that differences in recovery of adenylyl cyclase between individuals in small using the present method [11]. Second, the values for adenylyl cyclase in the control group were almost identical to those previously reported for another group of nondiabetic subjects [4].

It should be noted that only Type 2 diabetic patients with impaired glucose homeostasis were investigated. These patients were chosen for study in order to determine the importance of hyperglucagonaemia and hyperglycaemia in glucagon action. Therefore, it is unknown if glucagon action on liver membranes is altered in Type 2 diabetic patients with normal plasma glucose and glucagon levels.

The precise site of the alteration in glucagon action can be localised to three classes of functional proteins: (1) the glucagon receptor, (2) the adenylyl cyclase enzyme and (3) regulatory components $\left(\mathrm{N}_{\mathrm{s}}\right.$ and $\left.\mathrm{N}_{\mathrm{i}}\right)$ that couple hormone receptors to the cyclase enzyme [9]. A number of considerations argue against the involvement of the glucagon receptor. First, the glucagon binding activity of the receptor was not altered by the diabetic condition; both maximum glucagon binding and the binding affinity were normal in membranes from Type 2 diabetic patients. Second, the concentration of glucagon required to stimulate half-maximal cyclic AMP production was the same in both membrane preparations, indicating that sensitivity to the hormone was normal. Third, the alteration in cyclic AMP production was also observed with $\mathrm{NaF}$ and forskolin stimulation, agents that act at sites beyond the glucagon receptor [7, 8]. All of the results, including a depressed basal level of cyclic AMP production, support a post-receptor location for the defect in glucagon-stimulated adenylyl cyclase activity.

With the present results it is not possible to determine whether $\mathrm{N}_{\mathrm{s}}$, the stimulatory coupling protein, or the cyclase enzyme (or both) are sites of altered function. However, work by Dighe at al. [12] with streptozotocin-induced diabetic rats supports the hypothesis of a reduction in the activity of $\mathbf{N}_{\mathrm{s}}$. It was not possible in the study of diabetic rats to determine if a reduction in the adenylyl cyclase enzyme of liver membranes was also present. Finally, a third consideration for the post- 
receptor alteration is $\mathrm{N}_{\mathrm{i}}$, the inhibitory coupling component for adenylyl cyclase, which has been implicated in the depressed production of cyclic AMP by adipocyte membranes from ob/ob mice [13]. As with $\mathrm{N}_{s}$ and adenylyl cyclase, the experiments do not provide the information necessary to indicate or discount a role for this regulatory component in the altered response.

Several studies (see reference 12 for discussion) using the diabetic rat model have demonstrated a reduction in the level of the glucagon receptor [12]. This is the only major difference between the findings in the present studies with human liver membranes and those from the animal studies. A possible reason for the lack of an effect on the glucagon receptor in the human condition is the mild to moderate degree of hyperglucagonaemia; i. e., two-fold above normal, that may not be sufficient to induce receptor "down-regulation". The recent demonstration of normal glucagon binding activity by liver membranes from obese subjects, who had a two-fold elevation in fasting plasma glucagon levels, argues for this possibility [4]. Importantly, the presence of a post-receptor alteration rather than a specific receptor defect suggests that the effects of other hormones that act via the adenylyl cyclase system will be depressed in Type 2 diabetes. This concept is supported by a decrease in catecholamine stimulation of skeletal muscle adenylyl cyclase in the streptozotocin-diabetic rat model [14]. Thus, the reduced liver response to glucagon in diabetes may be non-specific. If so, the observed hyperglucagonaemia serves only to overcome the insensitivity of the adenylyl cyclase system.

It is of interest to discuss the present findings in relation to the metabolic derangements present in Type 2 diabetes mellitus. To obtain the full metabolic expression of diabetes mellitus, a decrease in insulin action and an increase in the action of glucagon are required [10]. In uncontrolled Type 2 diabetes, however, hyperglycaemia is often moderate and ketoacidosis is rarely present. Although there are likely a number of reasons why full expression of the metabolic alterations is not complete in this condition, the present work suggests an additional possibility. The reduction in the ability of glucagon to stimulate adenylyl cyclase activity blunts the hepatic production of glucose and ketones. However, the observation of a decrease in cyclic AMP formation at the post-receptor level has to be interpreted carefully in terms of glucose production and ketogenesis, since this single and early defect may be counterbalanced by alterations at more distal steps in glucagon action.

In summary, the present data show an overall decrease in the responsiveness of the hormone-sensitive adenylyl cyclase system in liver membranes from patients with Type 2 diabetes mellitus. This change seems to be localised at the post-receptor level and may involve alterations in the coupling proteins $\left(\mathrm{N}_{\mathrm{s}}\right.$ and $\left.\mathrm{N}_{\mathrm{i}}\right)$ or in the adenylyl cyclase enzyme. The concomitant loss of response to glucagon might be an adaptive compensation for the hyperglucagonaemia in Type 2 diabetes mellitus.

Acknowledgements. We thank Drs G. Lundqvist and L. Wide (University of Upsala, Sweden) for measuring the glucagon levels. This work was supported by National Institutes of Health grant AM 25116 and by grants from the Swedish Medical Research Council (No.25116). Nordic Insulin Foundation, Swedish Diabetes Association, Folksam Foundation, Osterman Foundation, Karolinska Institute, Groschinsky Foundation, and Swedish Medical Association.

\section{References}

1. Best JD, Judzewitsch RG, Pfeifer MA，Beard JC, Halter JB, Porte JRD (1982) The effect of chronic sulfonylurea therapy on hepatic glucose production in non-insulin dependent diabetes. Diabetes 31: 333-338

2. Unger RH, Orci L (1981) Glucagon and A cell. Physiology and pathophysiology (second of two parts). N Engl J Med 304: 1575-1580

3. Arner P, Einarsson K, Ewerth S, Livingston J (1986) Studies of the human liver insulin receptor in non-insulin-dependent diabetes mellitus. J Clin Invest 77: 1716-1718

4. Livingston JN, Einarsson $\mathrm{K}$, Backman L, Ewerth S, Arner P (1985) Glucagon receptor of human liver. Studies of its molecular weight and binding properties, and its ability to activate hepatic adenylyl cyclase of non-obese and obese subjects. J Clin Invest 75: $397-403$

5. Simpson IA, Sonne O (1982) A simple, rapid and sensitive method for measuring protein concentration in subcellular fractions prepared by sucrose density ultracentrifugation. Anal Biochem 119: 424-427

6. Scatchard G (1949) The attractions of proteins for small molecules and ions. Ann NY Acad Sci 51: 660-672

7. Kaslow HR, Johnsson GL, Brothers VM, Bourne HR (1980) A regulatory component of adenylate cyclase from human erythrocyte membranes. J Biol Chem 255: 3736-3741

8. Birnbaumer L, Stenge D, Desmier M, Hanoune J (1983) Forskolin regulation of liver membrane adenylyl cyclase. Eur $J$ Biochem 136: $107-112$

9. Rodbell M (1981) The actions of glucagon on the adenylate cyclase system. In: Unger RH, Orci L (eds) Glucagon. Elsevier North-Holland, New York, pp 177-193

10. Unger RH (1985) Glucagon physiology and pathophysiology in the light of new advances. Diabetologia $28: 574-578$

11. Amer P, Einarsson K, Backman L, Nilsell K, Lerea KM, Livingston JN (1983) Studies of liver insulin receptors in non-obese and normal weight humans. J Clin Invest 72: 1722-1736

12. Dighe RJ, Rojas FJ, Birnbaumer L, Garber GJ (1984) Glucagonstimulable adenylyl cyclase activity in rat liver. The impact of streptozotocin-induced diabetes mellitus. J Clin Invest 73: 1013-1023

13. Begin-Heick N (1985) Absence of the inhibitory effect of guanine nucleotides on adenylate cyclase activity in white adipocyte membranes of the ob/ob mouse. J Biol Chem 260: 6187-6193

14. Garber AJ (1980) The impact of streptozotocin-induced diabetes mellitus on cyclic nucleotide regulation of skeletal muscle amino acid metabolism in the rat. $\mathrm{J}$ Clin Invest $65: 478-487$

Received: 10 November 1986

and in revised form: 19 March 1987

Dr. P. Arner

Department of Medicine

Huddinge Hospital

S-14186 Huddinge

Sweden 